University of Zurich

Department of Economics

Working Paper Series

ISSN 1664-7041 (print)

ISSN 1664-705X (online)

Working Paper No. 332

\title{
Social Preference and Group Identity in the Financial Cooperative
}

Christian Ewerhart and Robertas Zubrickas

August 2019 


\title{
Social Preference and Group Identity in the Financial Cooperative*
}

\author{
Christian Ewerhart ${ }^{\dagger} \quad$ Robertas Zubrickas ${ }^{\ddagger}$
}

August 28, 2019

\begin{abstract}
We model the financial cooperative as an optimal institution sharing liquidity risks among agents with social preference and group identity. Stronger social concerns imply objectively better (worse) conditions for borrowers (depositors). Testing the model, we find that, indeed, deposit and loan rates offered by U.S. credit unions between 1995 and 2014 co-moved with (i) the number of members, and (ii) the common bond. Our theory explains how cooperatives coexist with banks, and why they have tended to be more resilient. However, the analysis also suggests that financial inclusion and advantages in resilience might quickly evaporate as membership requirements get diluted.
\end{abstract}

JEL codes. G21 Banks · Depository Institutions · Micro Finance Institutions · Mortgages; D91 Role and Effects of Psychological, Emotional, Social, and Cognitive Factors on Decision Making; L31 Nonprofit Institutions · NGOs · Social Entrepreneurship; G28 Government Policy and Regulation

Keywords. Social preferences · Group identity · Liquidity insurance · Cooperative banking $\cdot$ Credit union · Common bond · Bank competition $\cdot$ Resilience

*) Pablo Taborga Romero provided valuable research assistance.

†) (corresponding) Department of Economics, University of Zurich, Schönberggasse 1, 8001 Zurich, Switzerland; christian.ewerhart@econ.uzh.ch.

‡) Department of Economics, University of Bath, U.K.; r.zubrickas@bath.ac.uk. 


\section{Introduction}

Why are credit unions so popular? How do they create value for their members? How do they fend off competition, given that they are often very small? The existing literature has tended to provide answers to such questions predominantly by referring to the particularities of developing economies. For example, as suggested by the work of Stiglitz (1990) and Varian (1990), monitoring may be more cost-efficient in a small community than in a large anonymous market. Further, as discussed by Banerjee et al. (1994), there may be benefits of joint liability, similar to those identified for microfinance structures in the work of Besley and Coate (1995) and Armendáriz de Aghion (1999). However, these mechanisms seem to apply overall somewhat less to developed economies like the United States. ${ }^{1}$ The existing literature has also not been very successful in capturing the moral and ethical principles of the cooperative banking model, which have often been emphasized as its main distinctive feature. ${ }^{2}$

The present paper proposes an alternative way to think about the financial cooperative. Our approach is based on the observation that people living in the same community, working for the same employer, or sharing the same religion, tend to perceive themselves as members of a group, and that their individual well-being may depend to some extent also on the social situation in that reference group. ${ }^{3}$ Starting from this idea, we develop a social identity theory of the financial cooperative. Specifi-

\footnotetext{
${ }^{1}$ Relatedly, in the early days of the credit union, the common bond requirement may have served as a substitute for credit ratings (Goddard et al., 2008). However, the advent of nationwide credit bureaus seems to have eliminated most of this informational benefit (Walter, 2006).

${ }^{2}$ Indeed, financial cooperatives are typically mutually owned, stake-holder oriented, and set up as not-for-profit organizations (Groeneveld, 2014). Like many other cooperative institutions, they promote the values of self-help, self-responsibility, democracy, equality, equity, and solidarity (Groeneveld, 2011; International Co-operative Alliance, 2019).

${ }^{3}$ Needless to say, the psychological notion of social group identity (Tajfel and Turner, 1986) has been incorporated into the economics literature over the last two decades through contributions by Akerlof and Kranton (2000, 2005), Alesina and La Ferrara (2000), Goette et al. (2006), and Chen and Li (2009), among others. Similarly, the insight that social preferences enter decision-making has found its way into economic theory many years ago by the work of Loewenstein et al. (1989), Bolton (1991), Fehr and Schmidt (1999), and Bolton and Ockenfels (2000), in particular.
} 
cally, we argue that the possibility that other members of the cooperative end up with substantially less (or more) may be a concern for people, which may therefore create a demand for enhanced liquidity insurance that also accommodates such risk. Thus, we model the cooperative as a financial intermediary that offers services specifically for members of a group with some social identity. This approach proves to be both tractable and useful. In particular, our analysis suggests a way to reconcile existing institutional models of the credit union with mainstream banking theory. The theory explains how cooperative banks are able to compete with commercial banks even in the absence of informational advantages or differences in regulation. It also suggests a natural way for understanding why credit unions and banks prefer different governance structures. Last but not least, the model admits formal conclusions regarding the superior resilience of the financial cooperative.

The paper has two main parts: (i) theory, and (ii) empirical test. In the theoretical part, the financial cooperative is modeled as an optimal institution sharing liquidity risks (Bryant, 1980; Diamond and Dybvig, 1983), where we will initially assume a finite number of depositors (Green and Lin, 2003; Ennis and Keister, 2009). We show that the key findings of the traditional analysis extend to the case of social preferences. Specifically, the first-best allocation is seen to balance the (socially adapted) rate of return on market investments with the marginal rate of substitution between the respective (subjective) consumption levels of savers and borrowers. Moreover, demand deposit contracts implement the first best, just as in the case of selfish preferences. Our main theoretical result, however, concerns the comparative statics of objective consumption levels. Under mild assumptions, including non-excessive financial market returns and nonincreasing absolute risk aversion, we show that the first-period consumption level is monotone increasing in the parameters measuring the strength of social preference. Based on this result, we hypothesize that interest rates offered 
by the financial cooperative (i) correlate positively with the size of the cooperative's membership base, and (ii) vary with the nature of the cooperative's group identity.

To test these hypotheses, we compose accounting data of more than 6'300 U.S. credit unions in the period from 1995 to 2014, as well as macroeconomic data for the same period. Using this combined data set, we estimate the determinants of deposit and loan rates. It turns out that, all else equal, both interest rates are significantly higher in credit unions with a larger member base. This is consistent with the general empirical observation that, as the number of members of a group increases, there tends to be less identification with the group and less engagement for the achievement of common goals. ${ }^{4}$ Further, we observe significantly lower interest rates in community and faith-based credit unions than in occupational credit unions. Thus, the empirical analysis indeed provides some support for our theoretical predictions.

The remainder of this paper is structured as follows. Section 2 provides some institutional background. The theoretical analysis is presented in Section 3. Section 4 contains the empirical part. Extensions are discussed in Section 5. Section 6 concludes. Three appendices cover proofs, the case of constant relative risk aversion, and definitions of econometric variables, respectively.

\section{Institutional background}

In the US, the predominant form of financial cooperative is the credit union. According to the National Credit Union Administration (NCUA), there were 6'229 credit unions in 2014 that held assets worth USD 1.1 trillion, equivalent to $7 \%$ of total bank assets in the economy, and serving about 100 million member-customers. Since 1934, credit

\footnotetext{
${ }^{4}$ Related effects of group size on individual behavior have been documented in the psychological literature under the heading of diffusion of responsibility (Darley and Latané, 1968; Latané and Nida, 1981; Brewer and Kramer, 1986). In the economics literature, group size effects have been studied in public good games (Fleishman, 1980; Isaac and Walker, 1988; Isaac et al., 1994; Barron and Yechiam, 2002), in prisoner's dilemma settings (Diekmann, 1985), and for variants of the dictator game (Cason and Mui, 1997; Stahl and Haruvy, 2006; Panchanathan et al., 2013; Schuhmacher et al., 2017; Robson, 2018), in particular.
} 
unions must be registered as not-for-profit organizations that pursue the economic and social objectives of their members. The governance of credit unions follows a onemember-one-vote principle, and most offices are not compensated. Eligibility criteria for membership, known as the common bond, may be defined in terms of a community, association (e.g., church or fraternity), or occupation (Emmons and Schmid, 1999; Frame et al., 2002). Most credit unions are either (i) federally chartered, or (ii) state-chartered and federally insured. Those credit unions are regulated by NCUA, and their members are protected by the National Credit Union Share Insurance Fund (NCUSIF). The interests of U.S. credit unions are represented by the Credit Union National Association (CUNA). Over the past decades, credit unions have grown into full service financial providers, and have also become direct competitors to commercial retail banks (Feinberg, 2001). The fact that credit unions have remained exempt from federal income taxes continues to cause some controversy.

Besides the U.S., credit unions constitute an important part of the financial system in many other countries, including Ireland, Canada, and Australia, for instance. In the UK, however, the cooperative banking sector is represented mainly by several dozens of building societies. In continental Europe, the prevalent form of the financial cooperative is the cooperative bank. Cooperative banks are organized in large networks known as cooperative banking groups that accounted in 2016, on average, for more than $20 \%$ of the loan and deposit markets. In contrast to the U.S. model, there is no common bond requirement for customers. Notwithstanding, owing to a local business model, cooperative banks typically have a relatively homogeneous customer base. ${ }^{5}$

\footnotetext{
${ }^{5}$ For a more comprehensive account of the credit union in the U.S., we refer the reader to McKillop and Wilson (2011, 2015). The World Council of Credit Unions (2018) offers a global perspective. For the European market, see European Association of Co-operative Banks (2018).
} 


\section{Theory}

\subsection{The model}

We study the social interaction of a group of $n \geq 2$ ex-ante identical agents that are exposed to idiosyncratic liquidity shocks. There are two periods. In each period $t \in\{1,2\}$, the representative agent is endowed with a positive amount of $e_{t}>0$ units of the homogeneous consumption good. Endowments may be either consumed in the same period or traded in an anonymous financial market. Specifically, for any unit invested in period 1 , the market offers $R>1$ units in period 2. Similarly, for any unit given up in period 2 , the market offers $\frac{1}{R}$ units in period 1 . We denote by $c_{t}^{i} \in \mathbb{R}_{+}$ agent $i$ 's consumption in period $t \in\{1,2\}$.

At some anticipated point in time within period 1 , a given number $n_{1}$ of agents are randomly selected as impatient, while the remaining $n_{2}=n-n_{1}$ agents are patient. ${ }^{6}$ We will assume throughout that $n_{1} \geq 1$ and $n_{2} \geq 1$. Agent $i$ 's total consumption is defined as

$$
c^{i}=c_{1}^{i}+\theta^{i} c_{2}^{i}
$$

where $\theta^{i}=\underline{\theta} \in\left(0, \frac{1}{R}\right)$ if agent $i$ is impatient, and $\theta^{i}=\bar{\theta} \equiv 1$ if agent $i$ is patient. When there is no risk of confusion, we will refer to $c^{i}$ simply as $i$ 's objective consumption.

Following the literature on social preferences, in particular Fehr and Schmidt (1999) and Engelmann (2006), agent $i$ 's subjective consumption will be defined as

$$
\widetilde{c}^{i}=c^{i}-\frac{\alpha}{g(n)} \sum_{j \neq i} \max \left\{c^{j}-c^{i}, 0\right\}-\frac{\beta}{g(n)} \sum_{j \neq i} \max \left\{c^{i}-c^{j}, 0\right\},
$$

where $\alpha$ and $\beta$ are the usual envy and compassion parameters satisfying $\alpha \geq \beta \geq 0$ and $\beta<1$, while $g(n)$ is a normalization factor capturing group size $n$. Thus, each agent dislikes differences between her own objective consumption and any other agent's ob-

\footnotetext{
${ }^{6}$ Thus, we assume that the total number of patient agents is common knowledge. We conjecture though that our results do not depend on this simplifying assumption.
} 
jective consumption. ${ }^{7}$ Regarding group-size normalization, we assume that the ratio $\frac{g(n)}{n-1}$ is weakly increasing in $n$. Moreover, to ensure consistency with the literature on inequality aversion, we impose $g(2)=1$. For example, Fehr and Schmidt (1999) worked with the linear normalization $g(n)=n-1$, which obviously satisfies our assumptions. $^{8}$ Each agent $i$ maximizes her expected utility from subjective consumption, $E\left[U\left(\widetilde{c}^{i}\right)\right]$, where $U$ denotes the utility function, assumed to be twice continuously differentiable with $U^{\prime}>0$ and $U^{\prime \prime}<0$. It should be noted that an agent's utility depends only on her own objective consumption and on the empirical distribution of objective consumption levels in the relevant reference group.

Clearly, an impatient agent (a patient agent) arranges for consuming exclusively at the end of period 1 (period 2). In view of this fact, we define an allocation as a pair $\left(c_{1}, c_{2}\right)$, where $c_{1}$ and $c_{2}$, respectively, denote objective consumption levels for the impatient and for the patient type. The first-best allocation $\left(c_{1}^{*}, c_{2}^{*}\right)$ maximizes the ex-ante expected utility of the representative agent subject to the resource constraint implied by the trading possibilities in the financial market. To guarantee positive consumption levels in the first-best allocation, we assume that $U$ satisfies Inada's conditions, i.e., $\lim _{\widetilde{c} \rightarrow 0} U^{\prime}(\widetilde{c})=\infty$ and $\lim _{\widetilde{c} \rightarrow \infty} U^{\prime}(\widetilde{c})=0$. We also impose standard assumptions on relative risk aversion ensuring the efficiency of risk sharing, i.e., we assume $-\widetilde{c} U^{\prime \prime}(\widetilde{c}) / U^{\prime}(\widetilde{c})>1$ for any $\widetilde{c}>0$.

The following result characterizes the first-best allocation in our setup.

\footnotetext{
${ }^{7}$ In the present context, envy corresponds to the borrower's dissatisfaction with a perceived lack in solidarity, and compassion to the saver's desire to show responsibility vis-à-vis others that are in a disadvantaged position. For convenience, however, we will stick to the terminology commonly used in the literature on social preferences.

${ }^{8}$ For a dictator game with $n-1$ recipients, Engelmann (2012) argued that $g(n)$ should grow at a sublinear rate, e.g., $g(n)=\sqrt{n-1}$. Actually, that normalization does not satisfy our assumption. However, in our specific application, it seems more natural to allow for the possibility that $g$ grows at a superlinear rate (say, $g(n)=(n-1)^{\rho}$ with $\rho>1$ ), which reflects weaker and ultimately diminishing social preferences in a larger reference group. Obviously, this is also what the empirical analysis implies.
} 
Proposition 1. (First Best) Let

$$
\widetilde{R}=\frac{R-\beta \frac{n_{1} R+n_{2}}{g(n)}}{1+\alpha \frac{n_{1} R+n_{2}}{g(n)}} .
$$

If $\widetilde{R}>1$, then the first-best allocation $\left(c_{1}^{*}, c_{2}^{*}\right)$ is characterized by the marginal condition

$$
\frac{U^{\prime}\left(\tilde{c}_{1}^{*}\right)}{U^{\prime}\left(\tilde{c}_{2}^{*}\right)}=\widetilde{R}
$$

and the resource constraint

$$
n_{1} c_{1}^{*}+n_{2} \frac{c_{2}^{*}}{R}=n\left(e_{1}+\frac{e_{2}}{R}\right)
$$

where subjective consumption levels are given by

$$
\begin{aligned}
& \tilde{c}_{1}^{*}=c_{1}^{*}-\frac{\alpha n_{2}}{g(n)}\left(c_{2}^{*}-c_{1}^{*}\right), \\
& \tilde{c}_{2}^{*}=c_{2}^{*}-\frac{\beta n_{1}}{g(n)}\left(c_{2}^{*}-c_{1}^{*}\right) .
\end{aligned}
$$

In this case, $c_{1}^{*}<c_{2}^{*}$. If, however, $\widetilde{R} \leq 1$, then

$$
c_{1}^{*}=c_{2}^{*}=\frac{n\left(R e_{1}+e_{2}\right)}{n_{1} R+n_{2}} .
$$

Thus, as in the case of selfish agents, the first-best allocation balances a trade-off between efficiency and insurance. In contrast to the standard setting, however, the trade-off is biased as a consequence of the agents' social concerns. This is so because, when $\alpha$ or $\beta$ is positive, the disadvantageous treatment of the borrowers is a concern for both savers and borrowers. As a result, the cooperative attaches a lower value to an anonymous investment, and a higher value in making loans accessible for its 
members. We will refer to $\widetilde{R}$ as the socially adapted market rate of return. It is easy to see that $\widetilde{R} \leq R$. In Appendix $\mathrm{B}$, we derive explicit expressions for the first-best allocation in the case of constant relative risk aversion.

The proof of Proposition 1 considers two cases. In the first, the socially adapted market rate $\widetilde{R}$ exceeds one. Then, the first-best allocation implies heterogeneity in consumption, and balances $\widetilde{R}$ with the marginal rate of substitution between the respective subjective consumption levels of patient and impatient agents. In this case, the proof of Proposition 1 boils down to showing that the patient type is objectively weakly better off than the impatient type. In the second case, $\widetilde{R} \leq 1$. Then, the first-best allocation equalizes the respective subjective consumption levels of patient and impatient agents, so that the allocation is pinned down by the resource constraint. In the sequel, we will focus on the first case, i.e., the case of an interior solution, which also receives support from our empirical analysis.

\subsection{Demand deposit contracts}

When an agent signs a demand deposit contract, the agent's endowments in both periods become property of the cooperative. In return, the contract entails the right to borrow an agreed gross amount of $c_{1}$ in period 1, subject to the availability of loanable funds in the cooperative. Further, in period 2, the capital stock of the credit union is divided evenly among the members that did not receive a loan in period 1 (i.e., that either did not request a loan or did so in vain). Demands for loans in period 1 are served sequentially in random order. Those agents that applied for and successfully received a loan will be referred to as borrowers, while the remaining agents will be referred to as savers.

The formal description of a demand deposit contract promising a loan size of $c_{1}$ is straightforward. Suppose that all $n$ agents sign a deposit contract with the cooperative. Then, granting a number of $m$ loans will be feasible for the cooperative 
if and only if

$$
m c_{1} \leq n\left(e_{1}+\frac{e_{2}}{R}\right)
$$

However, if this condition is violated for the $m$-th applicant, no loan is extended, which may be seen as a form of credit rationing. ${ }^{9}$ But suppose now that $m<n$ members have received a loan in period 1 . Then, the level of objective consumption available in period 2 for any of the remaining $n-m$ members is given by

$$
\widehat{c}_{2}\left(m, c_{1}\right)=\frac{R\left(n e_{1}-m c_{1}\right)+n e_{2}}{n-m} .
$$

Note that $\widehat{c}_{2}\left(m, c_{1}\right) \geq 0$ as a consequence of (9). Moreover, if $m=n_{1}$, the consumption level $c_{2}=\widehat{c}_{2}\left(n_{1}, c_{1}\right)$ just corresponds to the objective level of consumption foreseen for each of the patient agents in period 2 .

In a symmetric Bayes-Nash equilibrium, any unilateral deviation leading to a positive subjective consumption for the deviating agent strictly lowers the utility for that agent. ${ }^{10}$ We call a demand deposit contract, augmented by a symmetric Bayes-Nash equilibrium, optimal if it maximizes the representative agent's ex-ante expected utility within the class of all deposit contracts.

Proposition 2. The optimal demand deposit contract implements the first-best consumption plan.

This result establishes a potentially important robustness property of demand deposit contracts. Even accounting for group identity, a simple bilateral demand deposit contract allows implementing the first-best allocation.

The proof of Proposition 2 checks incentive compatibility of truth-telling in the

\footnotetext{
${ }^{9}$ Thus, credit rationing may happen off the equilibrium in our framework. For an equilibrium analysis of credit rationing, see Canning et al. (2003).

${ }^{10}$ To ensure positive subjective consumption levels for any deviating agent, it would suffice to assume that $\alpha$ is not too large. See the proof of Proposition 2.
} 
presence of social concerns. The argument for the patient type depends on whether the deviation causes credit rationing in period 1 or not. In the case where the deviation does not cause rationing, it turns out that the objectively advantaged saver would never wish to become a disadvantaged borrower, even though the deviation lessens the borrower's envy. In the case where the deviation actually causes rationing, there is a lottery. With probability $\frac{1}{n_{1}+1}$, the deviation has no effect because the deviating agent gets rationed. With probability $\frac{n_{1}}{n_{1}+1}$, however, one of the impatient agents gets rationed. Again, it turns out that a deviation is not optimal for the patient type. To check incentive compatibility for the impatient type, we show that the deviator envies the borrowers. In sum, it turns out that the standard incentive compatibility consideration extends to the case of social concerns.

\subsection{Comparative statics}

In this subsection, we study the comparative statics of the optimal demand deposit contract with respect to $\alpha, \beta$, and $n$. The following assumption will be imposed.

Assumption 1. Market returns are not too high, i.e., $\ln R \leq 1$. Moreover, $U$ reflects nonincreasing absolute risk aversion.

These conditions are not entirely implausible. In addition, we observe that, under Assumption 1, the comparative statics takes a particularly simple form.

Proposition 3. (Comparative statics) Impose Assumption 1. Then,

(i) $c_{1}^{*}$ is monotone increasing, and $c_{2}^{*}$ monotone decreasing in both $\alpha$ and $\beta$;

(ii) $c_{1}^{*}$ is monotone decreasing, and $c_{2}^{*}$ monotone increasing in $n$ (keeping the population shares $\nu_{1}=n_{1} / n$ and $\nu_{2}=n_{2} / n$ constant $)$; and

(iii) the monotonicity in parts (i) and (ii) is strict provided that $\widetilde{R}>1$. 
Thus, as social preferences get stronger, the disadvantaged borrowers will receive better conditions while, conversely, the advantaged group of savers will have to give up some of their interest gains. Further, as the group size increases, the situation will deteriorate for the disadvantaged borrowers. In both cases, the monotonicity is strict in the interior. ${ }^{11}$

Unexpected to us, the mechanics of the comparative statics differs between $\alpha$ and $\beta$. As $\alpha$ gets larger, there are two effects. First, the socially adapted rate of return declines, which shifts the balance to the benefit of the disadvantaged borrowers. Second, the borrowers suffer more from envy, which leads to an additional compensation. These effects work in the same direction. In fact, Assumption 1 is not needed to derive the comparative statics with respect to $\alpha$. In contrast, an increase in $\beta$ causes two countervailing effects. First, as in the case of the envy parameter, the socially adapted rate of return declines, which benefits the borrowers. But second, depositors also suffer more from compassion, which is an effect working in the opposite direction. Under Assumption 1, the first effect can be shown to dominate the second. ${ }^{12}$

To prepare the empirical analysis, we translate the objective consumption levels for savers and borrowers, respectively, into deposit and loan rates via

$$
\begin{aligned}
\rho^{D} & =\frac{c_{2}-e_{2}}{e_{1}}-1, \\
\rho^{L} & =\frac{e_{2}}{c_{1}-e_{1}}-1 .
\end{aligned}
$$

Under Assumption 1 , both $\rho^{D}$ and $\rho^{L}$ are weakly declining (weakly increasing) in the degree to which members exhibit social preferences (in the number of members).

\footnotetext{
${ }^{11}$ While a similar comparative statics property may be expected for changes in risk aversion, that would not constitute a plausible rationale for the existence of credit unions. Indeed, such explanation would be at odds with the common bond requirement.

${ }^{12}$ In the absence of Assumption 1, the comparative statics of the compassion parameter is ambiguous. A numerical example illustrating this fact can be found in Appendix B.
} 


\section{Empirical analysis}

\subsection{Data and variables}

The data set combines credit union panel data with macroeconomic time series. The panel data has been collected from NCUA year-end call reports. It covers a total of 6'376 federally chartered and federally insured credit unions. The macroeconomic time series has been taken from the Richmond Fed's website. The combined data set covers the years 1995 through 2014, yielding a total of 119'519 observations.

Table I. Econometric variables

\begin{tabular}{ll}
\hline Variable & Interpretation \\
\hline Credit union specific variables & \\
DEP_RATE & Deposit rate \\
LOAN_RATE & Loan rate \\
MEMBERS & Number of current members \\
POT_MEM & Number of potential members \\
ASSETS & Total assets \\
EQUITY & Equity \\
RETURN & Net investment return \\
INCOME & Non-interest income \\
EXPENSES & Non-interest expenses \\
TOM & Type of membership (categorical) \\
STATE & State, federal district or territory (categorical) \\
CONV & Dummy for charter conversion \\
\hline Macroeconomic variables & \\
GDP & Real gross domestic product growth rate \\
CPI & Inflation rate \\
GOV_RATE & 1-year U.S. Treasury bill rate \\
LIBOR & 12-month London interbank offered rate \\
FIN_CRISIS & Financial crisis dummy for the years 2007-2009 \\
\hline Note: Definitions of the credit union specific numerical variables are provided in Appendix C. &
\end{tabular}

Table I provides an overview of the econometric variables. Credit union specific variables include nine numerical variables, two categorical variables, and a dummy. The 
numerical variables all have an immediate interpretation, so that we banished their definitions to Appendix C. The two categorical variables capture (i) the type of membership, discussed in more detail below, and (ii) the state, district, or territory that the credit union reported in its address. ${ }^{13}$ The dummy indicates charter conversion. I.e., provided that the charter changed from federal to state within the considered period, CONV takes the value of one starting from the year in which the charter changed. In all other instances, the variable takes the value of zero. The macroeconomic variables include growth rates for the real gross domestic product and consumer prices, respectively, secured and unsecured market interest rates, as well as a dummy for the financial crisis period.

Table II. Descriptive statistics

\begin{tabular}{|c|c|c|c|c|c|c|}
\hline \multirow[t]{2}{*}{ Variable } & \multirow[t]{2}{*}{ Mean } & \multicolumn{3}{|c|}{ Standard deviation } & \multirow[t]{2}{*}{ Min } & \multirow[t]{2}{*}{$\operatorname{Max}$} \\
\hline & & overall & between & within & & \\
\hline DEP_RATE & 2.32 & 1.54 & 0.68 & 1.41 & 0.06 & 5.70 \\
\hline LOAN_RATE & 8.04 & 2.17 & 1.52 & 1.69 & 4.38 & 14.24 \\
\hline MEMBERS & 8.16 & 1.48 & 1.51 & 0.21 & 5.04 & 11.81 \\
\hline POT_MEM & 9.34 & 2.11 & 2.05 & 0.76 & 5.52 & 14.80 \\
\hline ASSETS & 16.67 & 1.84 & 1.85 & 0.36 & 12.15 & 21.05 \\
\hline EQUITY & 14.59 & 1.75 & 1.76 & 0.38 & 10.19 & 18.80 \\
\hline RETURN & 3.82 & 4.22 & 1.12 & 4.09 & -0.30 & 14.97 \\
\hline INCOME & 11.27 & 2.87 & 2.83 & 0.87 & 3.09 & 16.75 \\
\hline EXPENSES & 13.32 & 1.86 & 1.88 & 0.37 & 8.55 & 17.53 \\
\hline GDP & 2.40 & 1.65 & - & - & -2.52 & 4.49 \\
\hline CPI & 2.37 & 0.96 & - & - & -0.36 & 3.84 \\
\hline GOV_RATE & 2.91 & 2.29 & - & - & 0.12 & 6.11 \\
\hline LIBOR & 3.44 & 2.23 & - & - & 0.56 & 6.87 \\
\hline
\end{tabular}

Note: Shown is the descriptive statistics for our numerical data. Categorical variables and dummies have been omitted. Interest rates and growth rates are in percentage points, while all other variables are in natural logs. For credit union data, min and max stand for the 1st and 99th percentile, respectively. The data is annual. Source: NCUA, Federal Reserve Bank of Richmond.

\footnotetext{
${ }^{13}$ Credit unions in our data set reported addresses in any of the 50 U.S. states, in the District of Columbia, in Guam, Puerto Rico, and the U.S. Virgin Islands.
} 


\subsection{Descriptive statistics}

The descriptive statistics of our data set is shown in Table II. For each numerical variable, the table reports the mean, standard deviations, and the range. In addition, we report cross-sectional ("between") and idiosyncratic ("within") standard deviations for the numerical panel data. ${ }^{14}$ The information shown in the table reflects the pronounced heterogeneity of the cooperative sector. In particular, as can be seen, credit unions differ very much in the size of their membership base.

Table III. Credit unions by common bond

\begin{tabular}{llrrrr}
\hline Type-of-membership & NCUA & \multicolumn{2}{c}{ Credit Unions } & \multicolumn{2}{c}{ Members } \\
category & codes & 1995 & 2014 & 1995 & 2014 \\
\hline Community & 0 & 480 & $1^{\prime} 101$ & $9^{\prime} 500$ & $15^{\prime} 000$ \\
Faith-based & 1,54 & 217 & 227 & $1^{\prime} 300$ & $2^{\prime} 000$ \\
Other associational & 2,3 & 78 & 104 & $3{ }^{\prime} 400$ & $2^{\prime} 500$ \\
Education & 4,34 & 694 & 431 & $8^{\prime} 400$ & $10^{\prime} 400$ \\
Government & 5,35 & 127 & 74 & $47^{\prime} 100$ & $159^{\prime} 600$ \\
Military & 6,36 & $1^{\prime} 051$ & 577 & $8^{\prime} 000$ & $9^{\prime} 700$ \\
Manufacturing (single) & $10-15$ & 576 & 174 & $4^{\prime} 500$ & $1^{\prime} 400$ \\
Services (single) & $20-23$ & 611 & 222 & $4^{\prime} 200$ & $5^{\prime} 300$ \\
Manufacturing (multiple) & $40-49$ & 574 & 351 & $8^{\prime} 100$ & $133^{\prime} 700$ \\
Services (multiple) & $50-53$ & 390 & 402 & $9^{\prime} 000$ & $9^{\prime} 500$ \\
Other single or multiple bond & 24,98 & 255 & 173 & $11^{\prime} 200$ & $23^{\prime} 000$ \\
State-chartered & 99 & 631 & $2^{\prime} 393$ & $7^{\prime} 700$ & $19^{\prime} 400$ \\
\hline All & $0-99$ & $5^{\prime} 684$ & $6{ }^{\prime} 229$ & $8^{\prime} 100$ & $16^{\prime} 000$ \\
\hline
\end{tabular}

Note: For each category of credit unions, the table shows (i) the defining set of NCUA codes, (ii) the number of reporting credit unions in 1995 and 2014, respectively, and (iii) the average number of members, again for the years 1995 and 2014, and rounded to hundreds. Source: NCUA, own calculations.

Table III offers some descriptive statistics of the categorical variable TOM. For each type-of-membership category, the table shows the corresponding NCUA code(s), the number of credit unions active in the years 1995 and 2014, respectively, and the

\footnotetext{
${ }^{14}$ In the credit union specific data, we discarded observations with nonpositive values of the logvariables as well as observations for which our interest rate variables exceeded one, as is common in the literature (Wheelock and Wilson, 2011; Malikov et al., 2018).
} 
average number of members in those years. As can be seen, there is a clear trend towards the state charter, which relaxes the common bond requirement (Birch, 2015).

\subsection{Hypotheses}

As discussed in the Introduction, our modeling is based upon the presumption that the strength of the group identity within a financial cooperative, and hence, the strength of social preferences, (i) diminishes in the number of members, and (ii) is dependent also on the nature of the common bond. This leads us to the following testable implications of our theoretical analysis, which will serve as hypotheses for our subsequent empirical analysis.

Hypothesis 1. Credit unions with a larger member base offer higher deposit rates, and require higher loan rates than credit unions with a smaller member base.

Hypothesis 2. The effect of the common bond has the same sign for deposit and loan rates.

\subsection{Empirical model}

To test our hypotheses, we consider the econometric model

$$
\begin{aligned}
\text { DEP_RATE }_{i, t} & =\delta_{0, i}^{\mathrm{D}}+\mathrm{CU}_{-} \mathrm{VAR}_{i, t}^{\prime} \boldsymbol{\delta}_{1}^{\mathrm{D}}+\mathrm{MACRO}_{-} \mathrm{VAR}_{t}^{\prime} \boldsymbol{\delta}_{2}^{\mathrm{D}}+\varepsilon_{i, t}^{\mathrm{D}} \\
\text { LOAN_RATE }_{i, t} & =\delta_{0, i}^{\mathrm{L}}+\mathrm{CU}_{-} \mathrm{VAR}_{i, t}^{\prime} \boldsymbol{\delta}_{1}^{\mathrm{L}}+\mathrm{MACRO}_{-} \mathrm{VAR}_{t}^{\prime} \boldsymbol{\delta}_{2}^{\mathrm{L}}+\varepsilon_{i, t}^{\mathrm{L}},
\end{aligned}
$$

where $\delta_{0, i}^{\mathrm{D}}$ and $\delta_{0, i}^{\mathrm{L}}$ are idiosyncratic effects, $\mathrm{CU}_{-} \mathrm{VAR}_{i, t}$ is a vector comprising all explanatory credit union specific variables, MACRO_VAR ${ }_{t}$ is the vector of the macroeconomic variables, $\boldsymbol{\delta}_{1}^{\mathrm{D}}, \boldsymbol{\delta}_{1}^{\mathrm{L}}, \boldsymbol{\delta}_{2}^{\mathrm{D}}$, and $\boldsymbol{\delta}_{2}^{\mathrm{L}}$ are the corresponding vectors of regression coefficients, and $\varepsilon_{i, t}^{\mathrm{D}}$ and $\varepsilon_{i, t}^{\mathrm{L}}$ are the error terms. We estimate our econometric model equation-by-equation using the random effects method. ${ }^{15}$

\footnotetext{
${ }^{15}$ The fixed effects method is not applicable because of the presence of dummies.
} 


\subsection{Results}

Table IV reports the main results of our regression analysis.

Table IV. Estimation results

\begin{tabular}{|c|c|c|}
\hline & DEP_RATE & LOAN_RATE \\
\hline \multicolumn{3}{|c|}{ Credit union specific variables } \\
\hline MEMBERS & $0.478^{* * *}$ & $1.357^{* * *}$ \\
\hline POT_MEM & $-0.088^{* * *}$ & $-0.103^{* * *}$ \\
\hline ASSETS & $1.188^{* * *}$ & $-0.782^{* * *}$ \\
\hline EQUITY & $-0.551^{* * *}$ & $-0.628^{* * *}$ \\
\hline RETURN & $0.041^{* * *}$ & $0.020^{* * *}$ \\
\hline INCOME & $-0.069^{* * *}$ & $-0.033^{* *}$ \\
\hline EXPENSES & $-0.896^{* * *}$ & -0.071 \\
\hline TOM & \multicolumn{2}{|c|}{ - see Table $V$ - } \\
\hline STATE & \multicolumn{2}{|c|}{ - not reported - } \\
\hline $\mathrm{CONV}$ & $-0.401^{* * *}$ & $-0.576^{* * *}$ \\
\hline \multicolumn{3}{|c|}{ Macroeconomic variables } \\
\hline GDP & $-0.034^{* * *}$ & $-0.079^{* * *}$ \\
\hline CPI & $-0.179^{* * *}$ & $-0.180^{* * *}$ \\
\hline GOV_RATE & $0.330^{* * *}$ & $0.366^{* * *}$ \\
\hline LIBOR & $0.139^{* * *}$ & $-0.068^{* *}$ \\
\hline FIN_CRISIS & $0.205^{* * *}$ & $-0.314^{* * *}$ \\
\hline$R^{2}$ (overall) & 0.65 & 0.38 \\
\hline Obs. & $119^{\prime} 519$ & $119^{\prime} 519$ \\
\hline
\end{tabular}

Note: Shown are the coefficients resulting from the random effects regression of the empirical model (13)-(14), where standard errors have been corrected for clustering on the credit union. The coefficients for the categorical variable TOM are shown in Table V below. The coefficients for the categorical variable STATE are not reported. $* / * * / * * *$ indicate significance levels of $p=0.05 / p=0.01 / p=0.001$, respectively.

We start with the most important observation, viz. that MEMBERS has a positive 
and significant coefficient both for the deposit rate and the loan rate. ${ }^{16}$ It is crucial to acknowledge that this finding is unlikely to be driven by the economies of scale related to cost savings per member. Indeed, deposit and loan rates are seen to co-move in the size of the membership base, which is in conflict with the natural implication of economies of scale. Thus, we indeed obtain support for Hypothesis 1.

The effects of the other credit union specific variables are broadly in line with expectation. The size of potential membership (POT_MEM) has a small negative effect on both interest rates. This suggests that social concerns are somewhat stronger in a credit union whose membership base is only a small subset of the potential membership base. The signs of the coefficients of ASSETS is consistent with the prevalent view in the literature that credit unions work under economies of scale (Wheelock and Wilson, 2011; Malikov et al., 2018). Next, more conservative equity standards (EQUITY) lead to lower dividends, but might also correlate with more conservative lending standards, thereby lowering the loan rates. The respective effects of net investment returns (RETURN) and non-interest income (INCOME) are very small. Operating costs (EXPENSES) translate into lower dividends, but do not seem to matter for loan rates. Finally, the coefficients of the conversion dummy CONV are negative and significant. Thus, credit unions that chose to relax their membership requirement tend to offer lower interest rates than credit unions that have always been state-chartered. We see this as evidence for Hypothesis 2. However, we will discuss the role of the common bond in more detail below.

Also the coefficients for the macroeconomic variables are overall plausible. Growth (GDP) and inflation (CPI) have a negative effect on interest rates. Further, we observe predominantly positive correlations between credit union rates and the benchmark rates GOV_RATE and LIBOR. Lastly, the regression indicates that during the

\footnotetext{
${ }^{16}$ Doubling the membership base is predicted to lead to an increase in the deposit rate by $0.478 \times$ $\ln (2) \times 100=33$ basis points and an increase in the loan rate by $1.357 \times \ln (2) \times 100=94$ basis points.
} 
financial crisis (FIN_CRISIS), credit unions offered better conditions not only for depositors (possibly to attract funds), but also for borrowers (possibly due to a more restrictive lending policy).

Table V. Common bond effects

\begin{tabular}{lcc}
\hline $\begin{array}{l}\text { Type-of-membership } \\
\text { category }\end{array}$ & DEP_RATE & LOAN_RATE \\
\hline Community & 0.000 & 0.000 \\
Faith-based & $-0.420^{* * *}$ & $-0.282^{*}$ \\
Other associational & $0.284^{* * *}$ & $0.330^{* *}$ \\
Education & $0.085^{* * *}$ & $0.111^{* *}$ \\
Government & $0.102^{* *}$ & $0.244^{* * *}$ \\
Military & $0.276^{* * *}$ & $0.227^{* * *}$ \\
Manufacturing (single) & $0.394^{* * *}$ & $0.175^{* * *}$ \\
Services (single) & $0.216^{* * *}$ & 0.092 \\
Manufacturing (multiple) & $0.170^{* * *}$ & $0.191^{* * *}$ \\
Services (multiple) & $0.115^{* * *}$ & $0.098^{*}$ \\
Other single and multiple bond & $0.106^{* * *}$ & $0.157^{* *}$ \\
State-chartered & $0.112^{* * *}$ & $0.164^{* *}$ \\
\hline
\end{tabular}

Note: Shown are the regression coefficients for the categorical variable TOM omitted from Table IV. The coefficients for the community category have been normalized to zero. */**/*** indicate significance levels of $p=0.05 / p=0.01 / p=0.001$, respectively.

\subsection{The common bond}

In Table $\mathrm{V}$, we report the regression coefficients of the categorical variable TOM. The coefficient for the community category has been normalized to zero. Thus, a negative (positive) coefficient suggests stronger (weaker) social concerns than in the average residential credit union. The role of the common bond is most salient in faith-based credit unions, as these unions set the lowest interest rates. Relative to the community category, all occupational credit unions set higher interest rates. Thus, the common bond moves interest rates for savers and borrowers in the same direction, indicating also here a comovement. We therefore see these findings as support for Hypothesis 2. 


\section{Extensions}

In this section, we discuss (1) the coexistence of cooperative and commercial banks, (2) the distributional conflict between savers and borrowers, and (3) the resilience of the financial cooperative.

\subsection{Coexistence of cooperative and commercial banks}

Our theoretical framework suggests a surprisingly simple answer to the question of how cooperatives may coexist with commercial banks. ${ }^{17}$ To see this, imagine a large population of agents with heterogeneous preferences for egalitarian treatment. Specifically, suppose that a share $\nu^{S}>0$ of the population is selfish for whom envy and compassion parameter vanish, and a share $\nu^{P}>0$ of the population is prosocial for whom envy and compassion parameters $\alpha$ and $\beta$ satisfy the assumptions made before. Further, we consider now social preferences with linear group-size normalization $g(n)=n-1$, as in Fehr and Schmidt (1999), and consider the limit for $n \rightarrow \infty$. To have heterogeneity, we assume that $\alpha>0$. In each of the two subpopulations, the probability of being impatient and patient is $\nu_{1}$ and $\nu_{2}$, respectively, where we assume $\nu_{1}>0$ and $\nu_{2}>0$. We will assume that profit-maximizing risk-neutral banks compete, under free entry, by offering an allocation $\left(c_{1}, c_{2}\right)$ to the agents. In fact, our argument allows also for the possibility that a subset of the competitors have a not-for-profit orientation. $^{18}$

Proposition 4. Suppose that $\widetilde{R}>1$. Then, the following two conclusions hold true:

(i) There is no pooling equilibrium.

(ii) There is a separating equilibrium in which all intermediaries earn zero profits.

\footnotetext{
${ }^{17}$ Differences in taxation in itself do not constitute a satisfactory explanation because, for example, numerous small banks in the U.S. are organized as Subchapter S corporations, and as a result, enjoy tax exemptions like most credit unions (Walter, 2006, pp. 363-364).

${ }^{18}$ Hart and Moore $(1996,1998)$ study how market performance of firms depends on governance. In the case of the financial cooperative, we believe that mutual ownership is a way to strengthen group identity. The empirical investigation of this relationship seems neglected though.
} 
Thus, the conclusions are similar to those known from the theory of competitive insurance markets (Rothschild and Stiglitz, 1976). Also the proof is similar. In fact, the proof is even simpler because a bank's profit from attracting an agent does not depend on whether the agent is selfish or prosocial. ${ }^{19}$ Specifically, noting that the first-best consumption pairs for selfish and prosocial agents differ by Proposition 3, one observes that a bank deviating from pooling could obtain positive profits by offering a consumption pair close to the first-best consumption pair for one of the two social preference types. As a result, a pooling equilibrium would not be robust against the corresponding deviation of an intermediary. Instead, a separating equilibrium can be constructed in which intermediaries offer allocations (or interest rate pairs) tailor-made either for selfish or for selfish agents.

\subsection{The distributional conflict between savers and borrowers}

The institutional literature on credit unions, represented by Taylor (1970), Walker and Chandler (1977), Smith et al. (1981), and Smith (1984), has tended to emphasize the conflict of interests between savers and borrowers. Smith (1984), for example, assumed that the credit union maximizes a weighted sum of lender and borrower margins under imperfect competition. Our model shares with those papers that the interest rate policy of the cooperative is a compromise between the opposing objectives of two different groups of members. Indeed, the first-best objective consumption plan in our model maximizes the ex-ante expected utility from subjective consumption,

$$
E[U]=\nu_{1} U\left(\widetilde{c}_{1}\right)+\nu_{2} U\left(\widetilde{c}_{2}\right)
$$

subject to the resource constraint. However, in contrast to the existing literature, the

\footnotetext{
${ }^{19}$ This would change, of course, if social preference and patience types were correlated. However, we conjecture that, under additional assumptions, the conclusion of Proposition 4 extends to correlated types.
} 
conflict between savers and borrowers is resolved here at the ex ante stage, i.e., before a member learns her type. Still, there is certainly a sense in which our analysis formally captures the important distributional conflict between savers and borrowers in a credit union, and thereby reconciles two hitherto independent strands of the literature. ${ }^{20}$

\subsection{Resilience of the financial cooperative}

It has been widely noted that U.S. credit unions have withstood the financial crisis much better than many banks (see, e.g., McKillop and Wilson, 2015). Relatedly, the credit union deposit insurance scheme survived the S\&L crisis of the 1980s without falling into a state of accounting insolvency and without any taxpayer bailout (Kane and Hendershott, 1996). Similarly, in continental Europe, co-operative banks generally hold larger reserves, and have lower but less volatile levels of profitability than commercial banks (European Association of Co-operative Banks, 2010). Cooperative banks were also responsible for a disproportionately small share of write-downs and financial aids during the crisis. $^{21}$

Our theoretical framework is consistent with these observations. Under the assumptions of Proposition 3, a preference for egalitarian treatment makes credit union members seek flatter consumption schedules in comparison to the optimal arrangement with selfish preferences. But a flatter consumption schedule has important implications for an intermediary's resilience against unanticipated shocks. Indeed, in our framework, net investment of the optimal liquidity-pooling institution is given by

$$
I=n e_{1}-n_{1} c_{1}^{*}
$$

\footnotetext{
${ }^{20}$ However, we have to leave for future work the integration of a dynamic perspective, as in Rubin et al. (2013).

${ }^{21}$ For a general and country-specific review of financial cooperatives and their performance during the crisis, see Crear (2009) and Birchall (2013). Hesse and Čihák (2007) offer a broader discussion of the role of the cooperative sector for financial stability.
} 
Therefore, as $\alpha$ or $\beta$ increases, $c_{1}^{*}$ rises, so that $I$ is declining. As a result, the cooperative designed for members with social preferences is predicted to be less exposed to an unanticipated shock in investment returns than its counterpart institution that is designed to serve customers with purely selfish preferences. ${ }^{22}$ Note also that our model implies an improved resilience for credit unions even in the absence of differences in governance. Therefore, our argument for resilience complements an earlier argument by Smith and Woodbury (2010) who attributed differences in resilience to governance issues.

Finally, our model predicts that an increase in $n$, keeping $\nu_{1}$ and $\nu_{2}$ fixed, raises the market exposure per saving individual, which is given by

$$
\frac{I}{n_{2}}=\frac{e_{1}}{\nu_{2}}-\frac{\nu_{1}}{\nu_{2}} c_{1}^{*}
$$

This lends support to the view that the recently observed dilution of common bond requirements, say, by conversion from federal charter to state charter, change to the community common bond, or by adopting multiple common bonds, may lead to less resilience in the cooperative sector (Frame et al., 2002; Ely, 2014; Birch, 2015). ${ }^{23}$

\section{Conclusion}

Both in the U.S. and abroad, the credit union and related institutional forms of the financial cooperative have established themselves as an important pillar of the modern financial industry. While specific benefits of the cooperative model have been iden-

\footnotetext{
${ }^{22}$ This comforting conclusion might dramatically change, however, in the absence of deposit insurance. As noted by Goldstein and Pauzner (2005), depository institutions may become more vulnerable to panic-based bank runs when they offer more risk sharing. Iyer and Puri (2012) provide empirical evidence that a stronger connectedness among depositors, which might be expected in a cooperative, can result in more contagious bank runs. Relatedly, Cassar and Wydick (2010) experimentally demonstrate that a socially grounded financial institution can be less stable with respect to individual deviating behavior than a standard financial institution.

${ }^{23}$ For a different view, see van Rijn (2018).
} 
tified for underdeveloped economies, the literature has struggled with explaining the distinctive nature of the financial cooperative in advanced economies.

In this paper, we have interpreted the financial cooperative as an intermediary that offers banking services to members of a group with some social identity. In this interpretation, members of the cooperative are not satisfied with insuring themselves against the risk of lower consumption, but they wish to take measures also to reduce the risk that they or others fall substantially behind within the group. As borrowers are disadvantaged compared to savers, these social concerns lead to better conditions for credit within the group, made possible by deposit rates for members that are below those that purely selfish behavior would imply. Moreover, as a larger fraction of the deposits gets invested in loans to members, there is less investment in anonymous markets, and consequently less exposure to shocks in the wider financial industry.

Our empirical findings unambiguously suggest a dilution of social concerns in credit unions with a larger membership base. We also observe that the type of the common bond, i.e., residential, associational, or occupational, plays a significant role for social concerns. These findings are in line with the large body of evidence regarding group identity and group size effects. For our specific application, these theories have important practical implications. Specifically, our analysis suggests that the beforementioned benefits of the cooperative banking model (viz. improved conditions for obtaining credit and higher resilience with respect to unanticipated shocks) are less likely to develop when the financial cooperative becomes too large, or when the common bond requirements are too much relaxed. 


\section{Appendix A. Proofs}

Proof of Proposition 1. The first-best consumption plan $\left(c_{1}^{*}, c_{2}^{*}\right)$ maximizes the representative agent's ex-ante expected utility subject to the resource constraint. Since $R>1$, patient types consume exclusively in period 2. Similarly, since $\underline{\theta} R<1$, impatient types consume exclusively in period 1 . Therefore, $\left(c_{1}^{*}, c_{2}^{*}\right)$ solves

$$
\begin{array}{ll}
\max _{c_{1}, c_{2}} & n_{1} U\left(\widetilde{c}_{1}\right)+n_{2} U\left(\widetilde{c}_{2}\right) \\
\text { s.t. } & \widetilde{c}_{1}=c_{1}-\frac{\alpha n_{2}}{g(n)} \max \left\{c_{2}-c_{1}, 0\right\}-\frac{\beta n_{2}}{g(n)} \max \left\{c_{1}-c_{2}, 0\right\} \\
& \widetilde{c}_{2}=c_{2}-\frac{\alpha n_{1}}{g(n)} \max \left\{c_{1}-c_{2}, 0\right\}-\frac{\beta n_{1}}{g(n)} \max \left\{c_{2}-c_{1}, 0\right\} \\
& n_{1} c_{1}+\frac{n_{2} c_{2}}{R} \leq n\left(e_{1}+\frac{e_{2}}{R}\right) .
\end{array}
$$

We begin the analysis of problem (18)-(21) by making two observations.

Lemma A.1 The resource constraint (21) is binding.

Proof. By contradiction. Suppose that $(21)$ held with strict inequality at $\left(c_{1}^{*}, c_{2}^{*}\right)$. Then, for $\varepsilon>0$ sufficiently small, the consumption plan $\left(c_{1}, c_{2}\right)=\left(c_{1}^{*}+\varepsilon, c_{2}^{*}+\varepsilon\right)$ satisfies (21). As a result, $\widetilde{c}_{1}>\widetilde{c}_{1}^{*}$ and $\widetilde{c}_{2}>\widetilde{c}_{2}^{*}$. Thus, the representative agent's expected utility could be raised, in conflict with the optimality of $\left(c_{1}^{*}, c_{2}^{*}\right)$.

Lemma A.2 $c_{1}^{*} \leq c_{2}^{*}$.

Proof. By contradiction. Suppose that $c_{1}^{*}>c_{2}^{*}$. Then, the envy (compassion) term vanishes for the borrowers (savers). Hence, $\left(c_{1}^{*}, c_{2}^{*}\right)$ locally solves

$$
\begin{array}{ll}
\max _{c_{1}, c_{2}} & n_{1} U\left(c_{1}-\frac{\beta n_{2}}{g(n)}\left(c_{1}-c_{2}\right)\right)+n_{2} U\left(c_{2}-\frac{\alpha n_{1}}{g(n)}\left(c_{1}-c_{2}\right)\right) \\
\text { s.t. } & n_{1} c_{1}+n_{2} \frac{c_{2}}{R}=n\left(e_{1}+\frac{e_{2}}{R}\right) .
\end{array}
$$


Letting $\lambda$ denote the multiplier of (23), the first-order necessary conditions read

$$
\begin{aligned}
& n_{1}\left(1-\frac{\beta n_{2}}{g(n)}\right) U^{\prime}\left(\widetilde{c}_{1}^{*}\right)-\frac{\alpha n_{1} n_{2}}{g(n)} U^{\prime}\left(\widetilde{c}_{2}^{*}\right)-\lambda n_{1}=0 \\
& \frac{\beta n_{1} n_{2}}{g(n)} U^{\prime}\left(\widetilde{c}_{1}^{*}\right)+n_{2}\left(1+\frac{\alpha n_{1}}{g(n)}\right) U^{\prime}\left(\widetilde{c}_{2}^{*}\right)-\lambda \frac{n_{2}}{R}=0
\end{aligned}
$$

where

$$
\begin{aligned}
& \widetilde{c}_{1}^{*}=c_{1}^{*}-\frac{\beta n_{2}}{g(n)}\left(c_{1}^{*}-c_{2}^{*}\right), \\
& \widetilde{c}_{2}^{*}=c_{2}^{*}-\frac{\alpha n_{1}}{g(n)}\left(c_{1}^{*}-c_{2}^{*}\right) .
\end{aligned}
$$

We eliminate $\lambda$ from the system of equations (24)-(25), and get

$$
\left(1-\beta \frac{n_{1} R+n_{2}}{g(n)}\right) U^{\prime}\left(\widetilde{c}_{1}^{*}\right)=\left(R+\alpha \frac{n_{1} R+n_{2}}{g(n)}\right) U^{\prime}\left(\widetilde{c}_{2}^{*}\right) .
$$

Since $U^{\prime}>0$, this implies $1-\beta \frac{n_{1} R+n_{2}}{g(n)}>0$. Therefore,

$$
\frac{U^{\prime}\left(\tilde{c}_{1}^{*}\right)}{U^{\prime}\left(\tilde{c}_{2}^{*}\right)}=\frac{R+\alpha \frac{R n_{1}+n_{2}}{g(n)}}{1-\beta \frac{R n_{1}+n_{2}}{g(n)}}
$$

The right-hand side of (29) clearly exceeds one. Hence, $U^{\prime}\left(\tilde{c}_{1}^{*}\right)>U^{\prime}\left(\tilde{c}_{2}^{*}\right)$. But then $U^{\prime \prime}<0$ implies that $\tilde{c}_{1}^{*}<\tilde{c}_{2}^{*}$. However, since $\beta<1$ and $n_{2} \leq n-1 \leq g(n)$,

$$
\tilde{c}_{1}^{*}-\tilde{c}_{2}^{*}=\left(c_{1}^{*}-c_{2}^{*}\right)\left(1+\frac{\alpha n_{1}}{g(n)}-\frac{\beta n_{2}}{g(n)}\right)>0 .
$$

The contradiction shows that $c_{1}^{*} \leq c_{2}^{*}$, as claimed.

By Lemma A.2, the compassion (envy) term vanishes for the borrowers (savers). Prob- 
lem (18)-(21) may, therefore, be rewritten as

$$
\begin{array}{ll}
\max _{c_{1}, c_{2}} & n_{1} U\left(c_{1}-\frac{\alpha n_{2}}{g(n)}\left(c_{2}-c_{1}\right)\right)+n_{2} U\left(c_{2}-\frac{\beta n_{1}}{g(n)}\left(c_{2}-c_{1}\right)\right) \\
\text { s.t. } & n_{1} c_{1}+\frac{n_{2} c_{2}}{R}=n\left(e_{1}+\frac{e_{2}}{R}\right) \\
& c_{1} \leq c_{2} .
\end{array}
$$

Let $\mu$ and $\nu$, respectively, denote the multipliers for constraints (32) and (33). We obtain the first-order conditions

$$
\begin{aligned}
n_{1}\left(1+\frac{\alpha n_{2}}{g(n)}\right) U^{\prime}\left(\tilde{c}_{1}^{*}\right)+\frac{\beta n_{1} n_{2}}{g(n)} U^{\prime}\left(\tilde{c}_{2}^{*}\right)-\mu n_{1}-\nu & =0, \\
-\frac{\alpha n_{1} n_{2}}{g(n)} U^{\prime}\left(\tilde{c}_{1}^{*}\right)+n_{2}\left(1-\frac{\beta n_{1}}{g(n)}\right) U^{\prime}\left(\tilde{c}_{2}^{*}\right)-\frac{\mu n_{2}}{R}+\nu & =0,
\end{aligned}
$$

where $\tilde{c}_{1}^{*}$ and $\tilde{c}_{2}^{*}$ are given by (6) and (7), respectively. In addition, we get the complementary slackness conditions

$$
\begin{aligned}
\nu & \geq 0, \\
\left(c_{1}^{*}-c_{2}^{*}\right) \nu & =0 .
\end{aligned}
$$

Eliminating the parameter $\mu$ in the linear system (34)-(35), and solving for the remaining parameter $\nu$, one arrives at

$$
\nu=\frac{n_{1} n_{2}}{n_{1} R+n_{2}}\left\{U^{\prime}\left(\tilde{c}_{1}^{*}\right)\left(1+\alpha \frac{n_{1} R+n_{2}}{g(n)}\right)-U^{\prime}\left(\tilde{c}_{2}^{*}\right)\left(R-\beta \frac{n_{1} R+n_{2}}{g(n)}\right)\right\} .
$$

Exploiting now the complementary slackness condition (36), this yields

$$
\frac{U^{\prime}\left(\tilde{c}_{1}^{*}\right)}{U^{\prime}\left(\tilde{c}_{2}^{*}\right)} \geq \widetilde{R}
$$


Moreover, from (37), a strict inequality feasible in (39) only if $c_{1}^{*}=c_{2}^{*}$. We will distinguish two cases.

Case 1. Suppose first that $\widetilde{R}>1$. Then, inequality (39) in combination with $U^{\prime \prime}<0$ implies $\tilde{c}_{1}^{*}<\tilde{c}_{2}^{*}$. But from

$$
\tilde{c}_{1}^{*}-\tilde{c}_{2}^{*}=\left(c_{1}^{*}-c_{2}^{*}\right)\left(1+\frac{\alpha n_{2}}{g(n)}-\frac{\beta n_{1}}{g(n)}\right)
$$

recalling that $\beta<1$ and $n_{1} \leq n-1$, it follows that $c_{1}^{*}<c_{2}^{*}$, so that (39) necessarily holds with equality.

Case 2. Suppose next that $\widetilde{R} \leq 1$. If, in addition, inequality (39) is strict, then $c_{1}^{*}=c_{2}^{*}$. If, however, relationship (39) holds with equality, then $U^{\prime}\left(\tilde{c}_{1}^{*}\right) \leq U^{\prime}\left(\tilde{c}_{2}^{*}\right)$, so that likewise $c_{1}^{*}=c_{2}^{*}$. Thus, either way, the claim follows from (5).

This concludes the proof of the proposition.

Proof of Proposition 2. It suffices to check incentive compatibility for patient and impatient agents.

Incentive Compatibility for the Patient Type. There are two cases. Suppose first that the cooperative's excess funds suffice to accommodate an additional loan request. In that case, the deviating patient agent receives a period- 1 consumption of $c_{1}^{*}$. Suppose for the moment that $n_{2} \geq 2$. Then, the additional loan request changes ${ }^{24}$ period-2 consumption of the $n_{2}-1$ remaining savers from $c_{2}^{*}=\widehat{c}_{2}\left(n_{1}, c_{1}^{*}\right)$ to $\widehat{c}_{2}=\widehat{c}_{2}\left(n_{1}+1, c_{1}^{*}\right)$. Hence, the incentive compatibility condition for a patient agent reads

$$
c_{1}^{*}-\alpha \frac{n_{2}-1}{g(n)} \max \left\{\widehat{c}_{2}-c_{1}^{*}, 0\right\}-\beta \frac{n_{2}-1}{g(n)} \max \left\{c_{1}^{*}-\widehat{c}_{2}, 0\right\} \leq \widetilde{c}_{2}^{*},
$$

\footnotetext{
${ }^{24}$ Because of our assumption on relative risk aversion, the objective consumption of the remaining savers is actually strictly declining by the deviation, but this fact is not needed in the proof.
} 
where $\widetilde{c}_{2}^{*}$ is given by (7). Subtracting $c_{1}^{*}$ on both sides of inequality (41) yields

$$
-\alpha \frac{n_{2}-1}{g(n)} \max \left\{\widehat{c}_{2}-c_{1}^{*}, 0\right\}-\beta \frac{n_{2}-1}{g(n)} \max \left\{c_{1}^{*}-\widehat{c}_{2}, 0\right\} \leq\left(1-\frac{\beta n_{1}}{g(n)}\right)\left(c_{2}^{*}-c_{1}^{*}\right) .
$$

The left-hand side of (42) is weakly negative. Moreover, since $c_{2}^{*} \geq c_{1}^{*}, n_{1} \leq n-1 \leq$ $g(n)$, and $\beta<1$, the right-hand side is weakly positive. Thus, (42) holds true. To deal with the case $n_{2}=1$, it suffices to note that the incentive compatibility condition in that case is given by $c_{1}^{*} \leq \widetilde{c}_{2}^{*}$, so that an analogous argument can be used.

Next, we consider the case in which a shortage of reserves prohibits the extension of more than $n_{1}$ loans. In that case, the sequential servicing constraint implies that the deviating patient agent is successful in receiving a loan with probability $\frac{n_{1}}{n_{1}+1}$, in which case one of the impatient agents becomes rationed, and remains unsuccessful with probability $\frac{1}{n_{1}+1}$. There are two subcases.

Suppose first that $c_{1}^{*}>\underline{\theta} c_{2}^{*}$. In this case, the deviating patient agent feels compassion when making the loan impossible for one of the impatient agents, and the incentive compatibility condition is given by

$$
\frac{n_{1}}{n_{1}+1} U\left(c_{1}^{*}-\alpha \frac{n_{2}-1}{g(n)}\left(c_{2}^{*}-c_{1}^{*}\right)-\frac{\beta}{g(n)}\left(c_{1}^{*}-\underline{\theta} c_{2}^{*}\right)\right)+\frac{1}{n_{1}+1} U\left(\widetilde{c}_{2}^{*}\right) \leq U\left(\widetilde{c}_{2}^{*}\right) .
$$

It is easy to see that condition (43) is equivalent to

$$
c_{1}^{*}-\alpha \frac{n_{2}-1}{g(n)}\left(c_{2}^{*}-c_{1}^{*}\right)-\frac{\beta}{g(n)}\left(c_{1}^{*}-\underline{\theta} c_{2}^{*}\right) \leq c_{2}^{*}-\frac{\beta n_{1}}{g(n)}\left(c_{2}^{*}-c_{1}^{*}\right) .
$$

Rewriting yields

$$
-\frac{\beta}{g(n)}\left(c_{1}^{*}-\underline{\theta} c_{2}^{*}\right) \leq\left(1+\alpha \frac{n_{2}-1}{g(n)}-\frac{\beta n_{1}}{g(n)}\right)\left(c_{2}^{*}-c_{1}^{*}\right)
$$

which holds as a consequence of $c_{2}^{*} \geq c_{1}^{*}, n_{1} \leq n-1 \leq g(n)$, and $\beta<1$. 
Suppose next that $c_{1}^{*} \leq \underline{\theta} c_{2}^{*}$, so that the deviating patient agent feels envy vis-a-vis all of the impatient agents, including the impatient agent that did not receive credit. In that case, the incentive compatibility condition reads

$$
\frac{n_{1}}{n_{1}+1} U\left(c_{1}^{*}-\alpha \frac{n_{2}-1}{g(n)}\left(c_{2}^{*}-c_{1}^{*}\right)-\frac{\alpha}{g(n)}\left(\underline{\theta} c_{2}^{*}-c_{1}^{*}\right)\right)+\frac{1}{n_{1}+1} U\left(\widetilde{c}_{2}^{*}\right) \leq U\left(\widetilde{c}_{2}^{*}\right),
$$

and the argument proceeds precisely as above. Thus, either way, the incentive compatibility condition for the patient agent holds.

Incentive Compatibility for the Impatient Type. Suppose that one of the impatient depositors deviates by not taking up a loan. Then, her objective consumption in period 1 is zero, while her objective consumption in period 2 becomes

$$
\widehat{c}_{2} \equiv \widehat{c}_{2}\left(n_{1}-1, c_{1}^{*}\right)=\frac{\left(n e_{1}-\left(n_{1}-1\right) c_{1}^{*}\right) R+n e_{2}}{n_{2}+1} .
$$

It is now useful to make the following observation.

Lemma A.3 The deviating impatient agent envies the borrowers, i.e., $\underline{\theta} \widehat{c}_{2}<c_{1}^{*}$.

Proof. Since by assumption $R \underline{\theta}<1$, it suffices to show that $\widehat{c}_{2}<R c_{1}^{*}$. Via (47), this is seen to be equivalent to $c_{1}^{*}>e_{1}+\frac{e_{2}}{R}$, which in turn is implied by our assumption that relative risk aversion exceeds one (cf. Diamond and Dybvig, 1983).

Given Lemma A.3, the incentive compatibility condition for the impatient agent ${ }^{25}$ reads

$$
\underline{\theta} \widehat{c}_{2}-\alpha \frac{n_{1}-1}{g(n)}\left(c_{1}^{*}-\underline{\theta} \widehat{c}_{2}\right)-\frac{\alpha n_{2}}{g(n)}(1-\underline{\theta}) \widehat{c}_{2} \leq \widetilde{c}_{1}^{*},
$$

\footnotetext{
${ }^{25}$ As mentioned in the body of the paper, to ensure that the LHS of inequality (48) is always positive, it would suffice to assume that $\alpha$ is not too large. To see why, note that from the efficiency of risk sharing, $c_{2}^{*}<R c_{1}^{*}$. Hence, using (47), $\widehat{c}_{2}>c_{2}^{*}$. Since, in addition, $c_{2}^{*} \geq c_{1}^{*}$ by Lemma A.2, we get $\widehat{c}_{2}>c_{1}^{*}$. Exploiting this fact, as well as $g(n) \geq n-1$, the LHS of inequality (48) is seen to be positive if $\alpha \leq \underline{\theta}$. Since $\underline{\theta} \in\left(0, \frac{1}{R}\right)$ is arbitrary, the claim indeed holds for any $\alpha<\frac{1}{R}$.
} 
where $\widetilde{c}_{1}^{*}$ is given by (6). Subtracting $c_{2}^{*}$ on both sides of inequality (48) leads to

$$
\underline{\theta} \widehat{c}_{2}-c_{2}^{*}-\alpha \frac{n_{1}-1}{g(n)}\left(c_{1}^{*}-\underline{\theta} \widehat{c}_{2}\right)-\frac{\alpha n_{2}}{g(n)}(1-\underline{\theta}) \widehat{c}_{2} \leq\left(1+\alpha \frac{n_{1}-1}{g(n)}\right)\left(c_{1}^{*}-c_{2}^{*}\right),
$$

which holds true because the right-hand side (left-hand side) is weakly positive (weakly negative). Hence, incentive compatibility holds also for the impatient agent. This completes the proof.

Proof of Proposition 3. Assume first that $\widetilde{R}>1$. Then, $U^{\prime}\left(\tilde{c}_{1}^{*}\right)-\widetilde{R} U^{\prime}\left(\tilde{c}_{2}^{*}\right)=0$, with $\tilde{c}_{1}^{*}$ and $\tilde{c}_{2}^{*}$ given by (6-7). Totally differentiating, we get

$$
\begin{gathered}
{\left[U^{\prime \prime}\left(\tilde{c}_{1}^{*}\right)\left(1+\frac{\alpha n_{2}}{g(n)}\right)-\widetilde{R} U^{\prime \prime}\left(\tilde{c}_{2}^{*}\right) \frac{\beta n_{1}}{g(n)}\right] d c_{1}^{*}} \\
+\left[U^{\prime \prime}\left(\tilde{c}_{1}^{*}\right)\left(-\frac{\alpha n_{2}}{g(n)}\right)-\widetilde{R} U^{\prime \prime}\left(\tilde{c}_{2}^{*}\right)\left(1-\frac{\beta n_{1}}{g(n)}\right)\right] d c_{2}^{*} \\
+\left[-U^{\prime \prime}\left(\tilde{c}_{1}^{*}\right) \frac{n_{2}}{g(n)}\left(c_{2}^{*}-c_{1}^{*}\right)-\widetilde{R}_{\alpha} U^{\prime}\left(\tilde{c}_{2}^{*}\right)\right] d \alpha \\
+\left[\widetilde{R} U^{\prime \prime}\left(\tilde{c}_{2}^{*}\right) \frac{n_{1}}{g(n)}\left(c_{2}^{*}-c_{1}^{*}\right)-\widetilde{R}_{\beta} U^{\prime}\left(\tilde{c}_{2}^{*}\right)\right] d \beta=0,
\end{gathered}
$$

where $\widetilde{R}_{\alpha}=\partial \widetilde{R} / \partial \alpha$ and $\widetilde{R}_{\beta}=\partial \widetilde{R} / \partial \beta$. Using $d c_{2}^{*}=-\frac{n_{1} R}{n_{2}} d c_{1}^{*}$, one finds that

$$
\lambda_{1} d c_{1}^{*}+\lambda_{\alpha} d \alpha+\lambda_{\beta} d \beta=0,
$$

with

$$
\begin{aligned}
& \lambda_{1}=U^{\prime \prime}\left(\tilde{c}_{1}^{*}\right)\left(1+\alpha \frac{n_{1} R+n_{2}}{g(n)}\right)+\widetilde{R} U^{\prime \prime}\left(\tilde{c}_{2}^{*}\right) \frac{n_{1}}{n_{2}}\left(R-\beta \frac{n_{1} R+n_{2}}{g(n)}\right), \\
& \lambda_{\alpha}=-U^{\prime \prime}\left(\tilde{c}_{1}^{*}\right) \frac{n_{2}}{g(n)}\left(c_{2}^{*}-c_{1}^{*}\right)-\widetilde{R}_{\alpha} U^{\prime}\left(\tilde{c}_{2}^{*}\right), \\
& \lambda_{\beta}=\widetilde{R} U^{\prime \prime}\left(\tilde{c}_{2}^{*}\right) \frac{n_{1}}{g(n)}\left(c_{2}^{*}-c_{1}^{*}\right)-\widetilde{R}_{\beta} U^{\prime}\left(\tilde{c}_{2}^{*}\right) .
\end{aligned}
$$


We claim that $\lambda_{1}<0$. Since the first term in (52) is negative, it suffices to show that

$$
R-\beta \frac{n_{1} R+n_{2}}{g(n)}>0
$$

but this follows immediately from $\widetilde{R}>1$. Thus, $\lambda_{1}$ is indeed negative. Moreover, $\lambda_{\alpha}>0$ is immediate, which proves claim (i) in the case where $\widetilde{R}>1$. Next, to see that $\lambda_{\beta}>0$, we will show that

$$
-\frac{U^{\prime \prime}\left(\tilde{c}_{2}^{*}\right)}{U^{\prime}\left(\tilde{c}_{2}^{*}\right)}\left(c_{2}^{*}-c_{1}^{*}\right)<-\frac{g(n)}{n_{1}} \frac{\widetilde{R}_{\beta}}{\widetilde{R}} .
$$

Because of

$$
\widetilde{R}_{\beta}=-\widetilde{R} \frac{\frac{n_{1} R+n_{2}}{g(n)}}{R-\beta \frac{n_{1} R+n_{2}}{g(n)}},
$$

condition (56) can be rewritten, together with

$$
c_{2}^{*}-c_{1}^{*}=\frac{\widetilde{c}_{2}^{*}-\widetilde{c}_{1}^{*}}{1+\frac{\alpha n_{2}}{g(n)}-\frac{\beta n_{1}}{g(n)}},
$$

as

$$
-\frac{U^{\prime \prime}\left(\widetilde{c}_{2}^{*}\right)}{U^{\prime}\left(\tilde{c}_{2}^{*}\right)}\left(\widetilde{c}_{2}^{*}-\widetilde{c}_{1}^{*}\right)<\frac{g(n)}{n_{1}} \frac{\frac{n_{1} R+n_{2}}{g(n)}}{R-\beta \frac{n_{1} R+n_{2}}{g(n)}}\left(1+\frac{\alpha n_{2}}{g(n)}-\frac{\beta n_{1}}{g(n)}\right) .
$$

We focus on the left-hand side of (59). Because of nonincreasing absolute risk aversion,

$$
-\frac{U^{\prime \prime}\left(\tilde{c}_{2}^{*}\right)}{U^{\prime}\left(\tilde{c}_{2}^{*}\right)}\left(\widetilde{c}_{2}^{*}-\widetilde{c}_{1}^{*}\right) \leq \int_{\tilde{c}_{1}^{*}}^{\tilde{c}_{2}^{*}}-\frac{U^{\prime \prime}(c)}{U^{\prime}(c)} d c=\ln \frac{U^{\prime}\left(\tilde{c}_{1}^{*}\right)}{U^{\prime}\left(\tilde{c}_{2}^{*}\right)}=\ln \widetilde{R} \leq \ln R \leq 1
$$

Next, we focus on the right-hand side of (59), and observe that

$$
\frac{g(n)}{n_{1}} \frac{\frac{n_{1} R+n_{2}}{g(n)}}{R-\beta \frac{n_{1} R+n_{2}}{g(n)}}\left(1+\frac{\alpha n_{2}}{g(n)}-\frac{\beta n_{1}}{g(n)}\right)>\frac{R}{R-\beta \frac{n_{1} R}{g(n)}}\left(1-\frac{\beta n_{1}}{g(n)}\right)=1
$$

This proves claim (ii) if $\widetilde{R}>1$. As for (iii), one notes that an increase in $n$, keeping $\nu_{1}$ 
and $\nu_{2}$ fixed, is equivalent to discounting $\alpha$ and $\beta$ by the same factor. The comparative statics with respect to $n$ follows, therefore, from parts (i) and (ii). The argument for $\widetilde{R}=1$ is similar, but uses directional derivatives. We omit the details. Finally, if $\widetilde{R}<1$, marginal effects on $\left(c_{1}^{*}, c_{2}^{*}\right)$ are obviously zero. The proposition follows.

Proof of Proposition 4. See the text following the proposition.

\section{Appendix B. Analysis of the CRRA specification}

In this section, we first derive the optimal contract in the case of constant relative risk aversion, and subsequently discuss the need for Assumption 1.

\section{B.1 Deriving the first best}

Suppose that $U(\widetilde{c})=\widetilde{c}^{1-\gamma} /(1-\gamma)$, where $\gamma>1$ is the Arrow-Pratt coefficient of relative risk aversion. This utility function satisfies our assumptions. ${ }^{26}$ In the boundary case $\widetilde{R} \leq 1$, the first-best allocation is given by equation (8) in Proposition 1 . It therefore suffices to discuss the case where $\widetilde{R}>1$. In this case, by Proposition 1 ,

$$
\frac{\widetilde{c}_{2}^{*}}{\widetilde{c}_{1}^{*}}=\widetilde{R}^{1 / \gamma},
$$

with

$$
\begin{aligned}
& \widetilde{c}_{1}^{*}=\left(1+\frac{\alpha n_{2}}{g(n)}\right) c_{1}^{*}-\frac{\alpha n_{2}}{g(n)} c_{2}^{*}, \\
& \widetilde{c}_{2}^{*}=\frac{\beta n_{1}}{g(n)} c_{1}^{*}+\left(1-\frac{\beta n_{1}}{g(n)}\right) c_{2}^{*} .
\end{aligned}
$$

Plugging (63) and (64) into (62), and recalling the budget constraint (5), we obtain a

\footnotetext{
${ }^{26}$ Indeed, $U$ has a coefficient of relative risk aversion strictly exceeding one everywhere, as assumed in the body of the paper. Note also that $U^{\prime}(\widetilde{c})=\widetilde{c}^{-\gamma}$ for any $\widetilde{c}>0$. In particular, $\lim _{\widetilde{c} \rightarrow 0} U^{\prime}(\widetilde{c})=-\infty$ and $\lim _{\widetilde{c} \rightarrow \infty} U^{\prime}(\widetilde{c})=0$. Thus, the Inada conditions hold. Finally, it is well-known (and easy to show) that the CRRA utility function exhibits nonincreasing absolute risk aversion.
} 
system of two linear equations in the parameters $c_{1}^{*}$ and $c_{2}^{*}$. Solving the system yields

$$
\begin{aligned}
& c_{1}^{*}=\left(e_{1}+\frac{e_{2}}{R}\right) \frac{n}{n_{1}+\frac{n_{2} \rho}{R}}, \\
& c_{2}^{*}=\left(e_{1}+\frac{e_{2}}{R}\right) \frac{n \rho}{n_{1}+\frac{n_{2} \rho}{R}}
\end{aligned}
$$

with

$$
\rho=\frac{\left(1+\frac{\alpha n_{2}}{g(n)}\right) \widetilde{R}^{1 / \gamma}-\frac{\beta n_{1}}{g(n)}}{1+\frac{\alpha n_{2}}{g(n)} \widetilde{R}^{1 / \gamma}-\frac{\beta n_{1}}{g(n)}} .
$$

Note that for $\alpha=\beta=0$, we simply have $\rho=R^{1 / \gamma}$, which corresponds to the solution in the standard model of liquidity insurance between purely selfish agents.

\section{B.2 Discussion of Assumption 1}

Using the explicit solution derived above, we can provide the promised example in which more compassion makes borrowers objectively worse off.

Example 1. Suppose that $U(\widetilde{c})=-1 / \widetilde{c}^{3}$, and that the normalization factor is $g(n)=$ $n-1$, as in Fehr and Schmidt (1999). The parameters of the model are $n_{1}=5, n_{2}=2$, $e_{1}=e_{2}=1$, and $R=4$. Then, the first-best allocation for $\alpha=0.01$ and $\beta=0.00$ is given by $\left(c_{1}^{*}, c_{2}^{*}\right)=(1.53513,2.14868)$. If, however, the compassion parameter is raised to $\beta=0.01$, then $\left(c_{1}^{*}, c_{2}^{*}\right)=(1.53512,2.14883)$, i.e., borrowers (savers) are worse (better) off in objective terms.

Example 1 fails to satisfy condition $\ln R \leq 1$. One can show (details omitted) that, similarly, the assumption of nonincreasing absolute risk aversion cannot be dropped without losing the monotone comparative statics property with respect to the compassion parameter. 


\section{Appendix C. Definitions of credit union specific variables}

All our numerical CU specific variables are defined in terms of NCUA account data. Table VII provides details.

Table VII. Call report definitions of econometric variables

\begin{tabular}{|c|c|c|}
\hline Variable & Definition & Description \\
\hline DEP_RATE & $\frac{\text { Acct_380 } 380_{t}+\text { Acct__381 }}{\text { Acct_018 }}$ & $\begin{array}{l}\text { Deposit rate: The sum of dividends on shares } \\
\text { (Acct_380) and interest on deposits (Acct_381) ac- } \\
\text { cumulated from Jan } 1 \text { to Dec } 31 \text { of year } t \text { over total } \\
\text { amount of shares and deposits (Acct_018) as of Dec } \\
31 \text { of year } t-1\end{array}$ \\
\hline LOAN_RATE & $\frac{\text { Acct__ } 110_{t}}{\text { Acct_025B } \mathrm{B}_{t-1}}$ & $\begin{array}{l}\text { Loan rate: Interest on loans (Acct_110) accumulated } \\
\text { from Jan } 1 \text { to Dec } 31 \text { of year } t \text { over total amount of } \\
\text { loans and leases (Acct_025B) as of Dec } 31 \text { of year } t-1\end{array}$ \\
\hline MEMBERS & Acct_ $083_{t}$ & Number of current members: As of Dec 31 of year $t$ \\
\hline POT_MEM & Acct_084t & Number of potential members: As of Dec 31 of year $t$ \\
\hline ASSETS & Acct_010 ${ }_{t}$ & Total assets: As of Dec 31 of year $t$ \\
\hline EQUITY & $\begin{array}{l}\text { Acct_931 }+ \text { Acct_668 } \\
\text { Acct_945 }+ \\
\text { Acct_9 Acct_65 } 60_{t}+\text { Acct_602 } \\
\text { Act }\end{array}$ & $\begin{array}{l}\text { Equity: The sum of regular reserves (Acct_931), } \\
\text { appropriation for non-conforming investments } \\
\text { (Acct_668), accumulated unrealized gains (losses) on } \\
\text { available-for-sale securities and other comprehensive } \\
\text { income (Acct_945), other reserves (Acct_658), undi- } \\
\text { vided earnings (Acct_940), net income (Acct_602) as } \\
\text { of Dec } 31 \text { of year } t\end{array}$ \\
\hline RETURN & $\frac{\text { Acct_ } 120_{t}+\text { Acct_} \_420_{t}}{\text { Acct_ } 799_{t-1}}$ & $\begin{array}{l}\text { Net investment return: Interest income from invest- } \\
\text { ments (Acct_120) plus gain (or loss) from the sale } \\
\text { of investments (Acct_420) accumulated from Jan } 1 \\
\text { to Dec } 31 \text { of year } t \text { over total investments (Acct_799 } \\
=\text { Acct_799I+Acct_730B+Acct_730C) as of Dec } 31 \text { of } \\
\text { year } t-1\end{array}$ \\
\hline INCOME & $\begin{array}{l}\text { Acct_131 }+ \text { +Acct_659 }+ \\
\text { Acct_430 } 4 \text { + Acct_440 }+\end{array}$ & $\begin{array}{l}\text { Non-interest income: The sum of fee income } \\
\text { (Acct_131), other operating income (Acct_659), gain } \\
\text { or loss on disposition of fixed assets (Acct_430) and } \\
\text { other non-operating income (Acct_440) accumulated } \\
\text { from Jan } 1 \text { to Dec } 31 \text { of year } t\end{array}$ \\
\hline EXPENSES & Acct_671 67 & $\begin{array}{l}\text { Non-interest expense: Accumulated from Jan } 1 \text { to } \\
\text { Dec } 31 \text { of year } t\end{array}$ \\
\hline
\end{tabular}




\section{References}

Akerlof, G.A., Kranton, R.E., 2000, Economics and identity, Quarterly Journal of Economics 115, 715-753.

Akerlof, G.A., Kranton, R.E., 2005, Identity and the economics of organizations, Journal of Economic Perspectives 19, 9-32.

Alesina, A., La Ferrara, E., 2000, Participation in heterogeneous communities, Quarterly Journal of Economics 115, 847-904.

Armendáriz de Aghion, B., 1999, On the design of a credit agreement with peer monitoring, Journal of Development Economics 60, 79-104.

Banerjee, V., Besley, T., Guinnane, T.W., 1994, Thy neighbor's keeper: The design of a credit cooperative with theory and a test, Quarterly Journal of Economics 109, 491-515.

Barron, G., Yechiam, E., 2002, Private e-mail requests and the diffusion of responsibility, Computers in Human Behavior 18, 507-520.

Besley, T., Coate, S., 1995, Group lending, repayment incentives and social collateral, Journal of Development Economics 46, 1-18.

Birch, R., 2015, "The FOM Debate: Why the trend toward state charters?" CUtoday, May 17, 2015.

Birchall, J., 2013, Resilience in a downturn: The power of financial cooperatives, International Labour Office (ILO), Geneva.

Bolton, G.E., 1991, A comparative model of bargaining: Theory and evidence, American Economic Review 81, 1096-1136.

Bolton, G.E., Ockenfels, A., 2000, ERC: A theory of equity, reciprocity, and competition, American Economic Review 90, 166-193. 
Brewer, M.B., Kramer, R.M., 1986, Choice behavior in social dilemmas: Effects of social identity, group size, and decision framing, Journal of Personality and Social Psychology 50, 543-549.

Bryant, J., 1980, A model of reserves, bank runs, and deposit insurance, Journal of Banking and Finance 4, 335-344.

Canning, D., Jefferson, C.V., Spencer, J.E., 2003, Optimal credit rationing in not-forprofit financial institutions, International Economic Review 44, 243-261.

Cason, T.N., Mui, V.-L., 1997, A laboratory study of group polarisation in the team dictator game, Economic Journal 107, 1465-1483.

Cassar, A., Wydick, B., 2010, Does social capital matter? Evidence from a five-country group lending experiment, Oxford Economic Papers 62, 715-739.

Chen, Y., Li, S.X., 2009, Group identity and social preferences, American Economic Review 99, 431-457.

Crear, S., 2009, Cooperative banks, credit union and the financial crisis, UN Expert Group Meeting on Cooperatives, New York.

Darley, J.M., Latané, B., 1968, Bystander intervention in emergencies: Diffusion of responsibility, Journal of Personality and Social Psychology 8, 377-383.

Diamond, D.W., Dybvig, P.H., 1983, Bank runs, deposit insurance, and liquidity, Journal of Political Economy 91, 401-419.

Diekmann, A., 1985, Volunteer's Dilemma, Journal of Conflict Resolution 29, 605-610. Ely, D., 2014, Credit unions and risk, Journal of Regulatory Economics 46, 80-111. Emmons, W.R., Schmid, F.A., 1999, Credit unions and the common bond, Federal Reserve Bank of St. Louis Review September/October, 41-64.

Engelmann, D., 2012, How not to extend models of inequality aversion, Journal of Economic Behavior \& Organization 81, 599-605. 
Ennis, H.M., Keister, T., 2009, Run equilibria in the Green-Lin model of financial intermediation, Journal of Economic Theory 144, 1996-2020.

European Association of Co-operative Banks, 2010, European Co-operative Banks in the Financial and Economic Turmoil: First Assessments, EACB research paper, available at www.eacb.coop.

European Association of Co-operative Banks, 2018, Co-operative Banks: At the Service of their Members and Society, The Publication of EACB \& Tilburg University, available at www.eacb.coop.

Fehr, E., Schmidt, K.M., 1999, A theory of fairness, competition and cooperation, Quarterly Journal of Economics 114, 817-868.

Feinberg, R.M., 2001, The competitive role of credit unions in small local financial services markets, Review of Economics and Statistics 83, 560-563.

Fleishman, J.A., 1980, Collective action as helping behavior: Effects of responsibility diffusion on contributions to a public good, Journal of Personality and Social Psychology 38, 629-637.

Frame, W.S., Karels, G.V., McClatchey, C., 2002, The effect of the common bond and membership expansion on credit union risk, Financial Review 37, 613-636.

Goddard, J., McKillop, D., Wilson, J.O.S., 2008, The diversification and financial performance of US credit unions, Journal of Banking $\&$ Finance 32, 1836-1849.

Goette, L., Huffman, D., Meier, S., 2006, The impact of group membership on cooperation and norm enforcement: Evidence using random assignment to real social groups, American Economic Review 96, 212-216.

Goldstein, I., Pauzner, A., 2005, Demand deposit contracts and the probability of bank runs, Journal of Finance 60, 1293-1328. 
Green, E.J., Lin, P., 2003, Implementing efficient allocations in a model of financial intermediation, Journal of Economic Theory 109, 1-23.

Groeneveld, H., 2014, The Spotlight on Financial Services Co-operatives, TIAS School for Business \& Society, Tilburg.

Groeneveld, J.M, 2011, Morality and integrity in cooperative banking, Ethical Perspectives 18, 515-540.

Hart, O., Moore, J., 1996, The governance of exchanges: Members' cooperatives versus outside ownership, Oxford Review of Economic Policy 12, 53-69.

Hart, O., Moore, J., 1998, Cooperatives vs. outside ownership, Working Paper W6421, National Bureau of Economic Research.

Hesse, H., Čihák, M., 2007, Cooperative Banks and Financial Stability, IMF working paper $07 / 2$.

International Co-operative Alliance, 2019, www.ica.coop/cooperatives/cooperativeidentity\#cooperative-values, accessed July 31, 2019.

Isaac, R.M., Walker, J.M., 1988, Group size effects in public goods provision: The voluntary contributions mechanism, Quarterly Journal of Economics 103, 179-199.

Isaac, R.M., Walker, J.M., Williams, A.W., 1994, Group size and the voluntary provision of public goods: Experimental evidence utilizing large groups, Journal of Public Economics 54, 1-36.

Iyer, R., Puri, M., 2012, Understanding bank runs: The importance of depositor-bank relationships and networks, American Economic Review 102, 1414-1445.

Kane, E.J., Hendershott, R., 1996, The federal deposit insurance fund that didn't put a bite on U.S. taxpayers, Journal of Banking and Finance 20, 1305-1327.

Latané, B., Nida, S., 1981, Ten years of research on group size and helping, Psychological Bulletin 89, 308-324. 
Loewenstein, G., Bazerman, M., Thompson, L., 1989, Social utility and decision making in interpersonal contexts, Journal of Personality and Social Psychology LVII, 426-441.

Malikov, E., Restrepo-Tobón, D.A., Kumbhakar, S.C., 2018, Heterogeneous credit union production technologies with endogenous switching and correlated effects, Econometric Reviews 37, 1095-1119.

McKillop, D., Wilson, J.O.S., 2011, Credit unions: A theoretical and empirical overview, Financial Markets, Institutions $\&$ Instruments 20, 79-123.

McKillop, D.G., Wilson, J.O.S., 2015, Credit unions as cooperative institutions: Distinctiveness, performance and prospects, Social and Environmental Accountability Journal 35, 96-112.

Panchanathan, K., Frankenhuis, W.E., Silk, J.B., 2013, The bystander effect in an $N$ person dictator game, Organizational Behavior and Human Decision Processes 120, 285-297.

Robson, M., 2018, Inequality Aversion and Self-Interest: An Experimental Approach, Ph.D. Thesis, University of York.

Rothschild, M., Stiglitz, J., 1976, Equilibrium in competitive insurance markets: An essay on the economics of imperfect information, Quarterly Journal of Economics 90, 629-647.

Rubin, G.M., Overstreet Jr., G.A., Beling, P., Rajaratnam, K., 2013, A dynamic theory of the credit union, Annals of Operations Research 205, 29-53.

Schumacher, H., Kesternich, I., Kosfeld, M., Winter, J., 2017, One, two, many Insensitivity to group size in games with concentrated benefits and dispersed costs, Review of Economic Studies 84, 1346-1377.

Smith, D.J., 1984, A theoretic framework of the analysis of credit union decision making, Journal of Finance 39, 1155-1168. 
Smith, D.J., Cargill, T.F., Meyer, R.A., 1981, Credit unions: An economic theory of a credit union, Journal of Finance Papers and Proceedings 36, 519-528.

Smith, D.M., Woodbury, S.A., 2010, Withstanding a Financial Firestorm: Credit Unions vs. Banks, Filene Research Institute.

Stahl, D.O., Haruvy, E., 2006, Other-regarding preferences: Egalitarian warm glow, empathy, and group size, Journal of Economic Behavior and Organization 61, 20-41. Stiglitz, J.E., 1990, Peer monitoring and credit markets, World Bank Economic Review 4, 351-366.

Tajfel, H., Turner, J.C., 1986, The social identity theory of intergroup behavior. In S. Worchel \& W. Austin (Eds.), Psychology of intergroup relations (pp. 7-24). Chicago: Nelson-Hall.

Taylor, R.A., 1971, The credit union as a cooperative institution, Review of the Social Economy 29, 207-217.

van Rijn, J., 2018, The effect of membership expansion on credit union risk and returns, No. 588, University of Wisconsin, Agricultural and Applied Economics.

Varian, H., 1990, Monitoring agents with other agents, Journal of Institutional and Theoretical Economics 146, 153-174.

Walker, M.C., Chandler, G.G., 1977, On the allocation of the net monetary benefits of credit union membership, Review of the Social Economy 35, 159-168.

Walter, J.R., 2006, Not your father's credit union, FRB Richmond Economic Quarterly 92, 353-377.

Wheelock, D.C., Wilson, P.W., 2011, Are credit unions too small? Review of Economics and Statistics 93, 1343-1359.

World Council of Credit Unions, 2018, Statistical Report 2017, updated November 2018, available at www.woccu.org. 